\section{OPEN ACCESS}

Edited by:

Henrique Barros,

University of Porto, Portugal

Reviewed by:

Lama Charafeddine,

American University of

Beirut, Lebanon

Jean-Christophe Mercier,

Université de Paris, France

*Correspondence:

Ali Ghanchi

ali.ghanchi@aphp.fr

Specialty section

This article was submitted to General Pediatrics and Pediatric

Emergency Care,

a section of the journal

Frontiers in Pediatrics

Received: 06 March 2021

Accepted: 30 April 2021

Published: 28 May 2021

Citation:

Ghanchi A, Rahshenas M, Bonnet D,

Derridj N, LeLong N, Salomon LJ, Goffinet $F$ and Khoshnood B (2021) Prevalence of Growth Restriction at Birth for Newborns With Congenital Heart Defects: A Population-Based Prospective Cohort Study EPICARD.

Front. Pediatr. 9:676994.

doi: 10.3389/fped.2021.676994

\title{
Prevalence of Growth Restriction at Birth for Newborns With Congenital Heart Defects: A Population-Based Prospective Cohort Study EPICARD
}

\begin{abstract}
Ali Ghanchi ${ }^{1,2 *}$, Makan Rahshenas ${ }^{1}$, Damien Bonnet ${ }^{3,4}$, Neil Derridj $^{1,3}$, Nathalie LeLong ${ }^{1}$, Laurent J. Salomon ${ }^{2,4}$, Francois Goffinet ${ }^{1,5}$ and Babak Khoshnood ${ }^{1}$ on behalf of the EPICARD Study Group
\end{abstract}

${ }^{1}$ Université de Paris, CRESS, INSERM, INRA, Paris, France, ${ }^{2}$ Service d'Obstétrique - Maternité, Chirurgie Médecine et Imagerie Foetales. APHP. Hôpital Necker Enfants Malades, Paris, France, ${ }^{3}$ Department of Pediatric Cardiology, M3C-Necker. APHP. Hôpital Necker-Enfants Malades, Paris, France, ${ }^{4}$ University of Paris, Paris, France, ${ }^{5}$ Port-Royal Maternity Unit, Cochin Hospital, APHP, Paris, France

Background and Objectives: Congenital heart defects (CHD) and growth restriction at birth are two major causes of childhood and adult morbidity and mortality. The aim of this study was to assess the overall risk of growth restriction at birth, as measured by its imperfect proxy small ( $<10$ th percentile) for gestational age (SGA), for newborns with $\mathrm{CHD}$.

Methods: Using data from a population-based cohort of children born with $\mathrm{CHD}$, we assessed the risk of growth restriction at birth using SGA and severe SGA (3rd percentile). To compare the odds of SGA and severe SGA across five specific major CHD, we used ordinal logistic regression using isolated, minor (non-operated) ventricular septal defect (VSD) as the control group.

Results: The overall proportion of SGA for "isolated" CHD (i.e., those not associated with other anomalies) was 13\% (95\% Cl, 12-15\%), which is 30\% higher than what would be expected in the general population (i.e., 10\%). The risk of severe SGA was 5\% (95\% $\mathrm{Cl}, 4-6 \%)$ as compared with the expected $3 \%$ in the general population. There were substantial differences in the risk of overall SGA and more so severe SGA across the different CHD. The highest risk of SGA occurred for Tetralogy of Fallot (adjusted OR 2.7, $95 \% \mathrm{Cl}, 1.3-5.8$ ) and operated VSD (adjusted OR 2.1, 95\% Cl, 1.1-3.8) as compared with the control group of minor (non-operated) VSD.

Conclusion: The overall risks of both SGA and severe SGA were higher in isolated $\mathrm{CHD}$ than what would be expected in the general population with substantial differences across the subtypes of CHD. These results may provide a clue for understanding the underlying mechanisms of the relation between alterations in fetal circulation associated with different types of CHD and their effects on fetal growth.

Keywords: small for gestational age, congenital heart defects, population-based cohort, prevalence, ordinal logistic regression 


\section{INTRODUCTION}

Congenital heart defects (CHD) are the most frequent group of congenital anomalies with a prevalence of about $1 \%$ of all births $(1,2)$. Newborns with CHD are at a higher risk of growth restriction at birth (3-5). The latter may be an independent risk factor for adverse outcomes in newborns with CHD (5).

By far most of the previous studies that investigated the relation between CHD and growth restriction were hospitalbased and population-based studies remain rare (3). Some of the literature has the shortcoming of including CHD associated with chromosomal or other anomalies without separate analyses of "isolated" CHD (not associated with chromosomal or other anomalies). Hence, the effects associated with the CHD per se are not always clear. Moreover, the specific effects of different types of $\mathrm{CHD}$ on the risk of growth restriction has not been adequately studied. Such an analysis may provide clues about the possible underlying mechanisms of the associations between CHD and growth restriction.

We used data from a population-based, prospective cohort study of more than 2,000 newborns with CHD to: (i) Assess the overall risk of growth restriction at birth for newborns with isolated CHD and to: (ii) Compare the risk and severity of growth restriction for five major types of CHD.

\section{MATERIALS AND METHODS}

\section{Data Source}

The EPICARD study was a population based prospective cohort of children born with CHD in the Greater Paris area (Paris and its surrounding suburbs) of France carried out between 2005 and 2008.

All cases (live births, terminations of pregnancy for fetal anomaly, TOPFA and fetal deaths) diagnosed prenatally or up to 1 year of age were eligible for inclusion. Diagnoses of CHD and associated comorbidities (i.e., genetic, extra cardiac anomalies and/or syndromes) were confirmed by specialized pediatric cardiologists. Detailed description of the EPICARD cohort has been provided elsewhere (6).

From the EPICARD cohort of all live births $(N=2,348)$, we excluded 112 multiple pregnancies and ten subjects with missing data on birthweight and/or gestational age. Newborns with chromosomal anomalies $(n=142)$ or anomalies of other systems and/or genetic syndromes $(n=295)$ were also excluded from the study population. Our final study population comprised 1,789 singleton newborns with isolated CHD and known birthweight and gestational age (Figure 1).

\section{Outcome and Predictor Variables}

The outcome variable, Small for Gestational Age (SGA) was defined as sex- and gestational age-specific birthweight $<10$ th percentile based on the EPOPé population-based growth curves (7). We defined severe SGA using the cut-off birthweight $<3$ rd

Abbreviations: CHD, Congenital Heart defects; VSD, Ventricular Septal Defects; CoA, Coarctation of the Aorta; ToF, Tetralogy of Fallot; TGA, Transposition of the Great Arteries; FUH, Functionally Univentricular Heart; SGA, Small for Gestational Age; TOPFA, Termination of Pregnancy for Fetal anomaly.

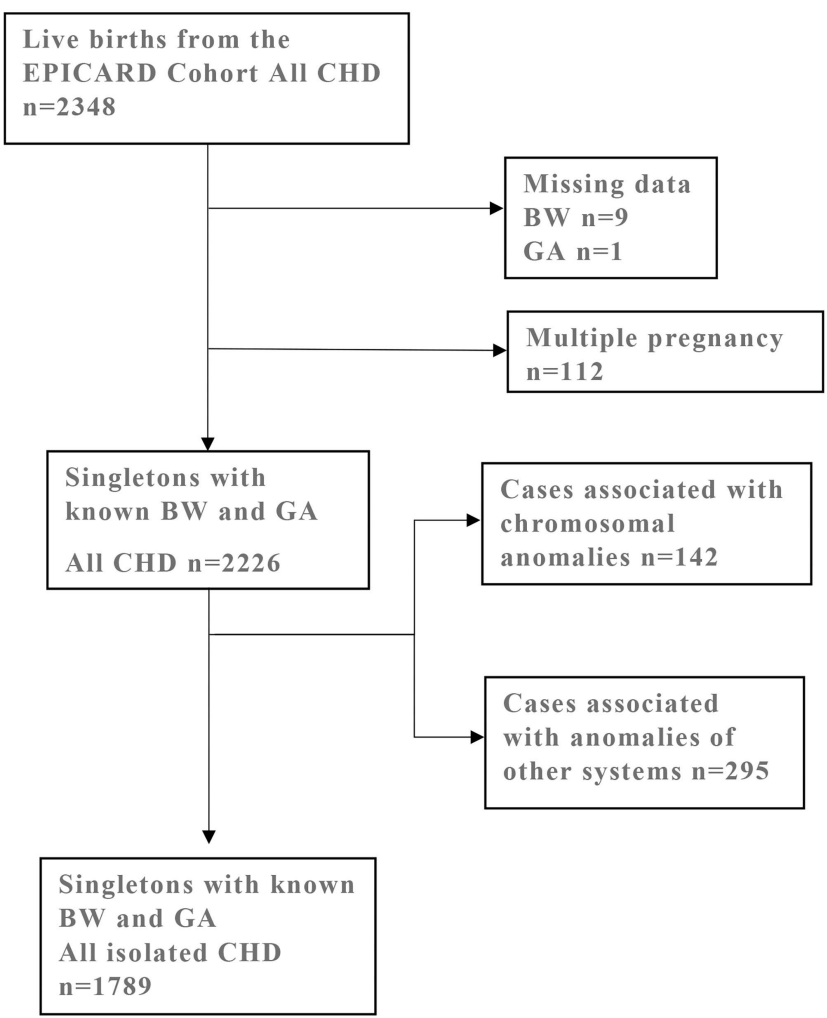

FIGURE 1 | Selection of study population from the EPICARD Cohort of live birth born with all CHD. CHD, congenital heart defects; BW, birth weight; GA, gestational age.

percentile and Intermediate SGA as birthweights between the 3rd $<10$ th percentiles. Not -SGA was defined based on birthweight $\geq 10$ th percentile (8).

The main predictor variable of interest was type of CHD. We also took into account a set of potentially confounding variables including maternal diabetes, hypertension, smoking, maternal age, geographic origin, parity, prenatal diagnosis, infertility treatments, sex and preterm $(<37$ weeks) delivery.

\section{Statistical Analysis}

As the outcome variable comprised ordered outcomes (severe SGA/intermediate SGA/Not SGA) we used ordinal logistic regression for the statistical analysis. The proportional odds assumption for the ordinal logit models was tested and the models were found to be consistent with a proportional odds model.

The proportional odds model considers the cumulative probability of an individual event and all other events that are ordered before it (Box 1) $(9,10)$. Whereas, binary logistic regression uses the logit (log odds) function, ordinal logistic regression uses the logit transformation of the cumulative odds. In the proportional odds logit model, the slopes that correspond to the model coefficients are parallel to one another and the odds for each cut-off category differ only with regards to the intercept (Box 1). The $\chi^{2}$-test for the proportional odds assumption 


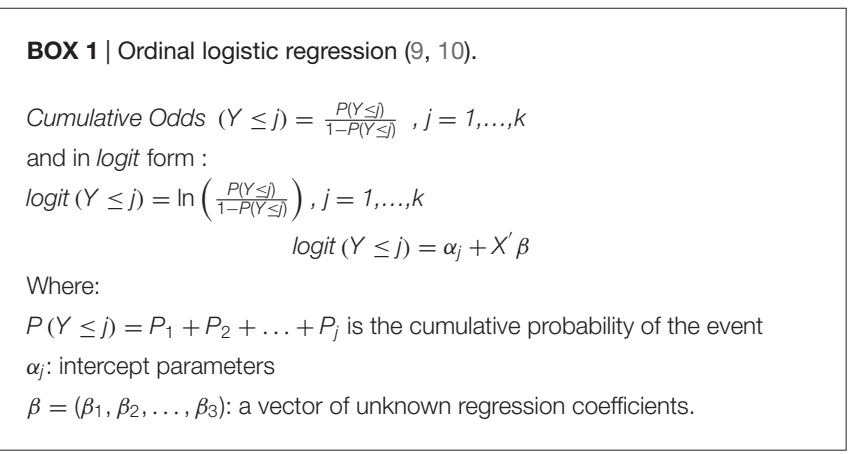

suggested that this was a reasonable assumption in the case of our models.

The statistical significance level was set at $\alpha=0.05$ and all analyses were done using Stata v15.1 software (StataCorp LP, College Station, TX, USA).

Ethics approval was obtained from the CNIL (Commission nationale de l'informatique et des libertés) (6).

\section{RESULTS}

Table 1 shows characteristics of the study population. Overall, 1,789 newborns with isolated CHD (not associated with chromosomal or other anomalies) were included in the study population. Of those, $47 \%$ were boys and $11 \%$ born preterm. Approximately $3 \%$ of women reported smoking during pregnancy, $1 \%$ had diabetes and $1 \%$ reported illicit drug use. Maternal age was 35 years or older for one quarter of women. One half of women were of French origin and 19\% of North African origin. Approximately $7 \%$ of the study population were born after infertility treatments and $17 \%$ had a prenatal diagnosis of the CHD.

Table 2 shows the proportions of SGA and severe SGA for isolated CHD and isolated specific CHD. The prevalence of SGA for isolated $\mathrm{CHD}$ was $13 \%(95 \% \mathrm{CI} 12-15 \%)$ and $5 \%(95 \% \mathrm{CI}$ 4-6\%) for severe SGA. For specific CHD, SGA, ranged from $10 \%$ (95\% CI 9-12\%) for minor non-operated VSD to $26 \%$ (95\% CI 16-40\%) for Tetralogy of Fallot (ToF). Severe SGA proportions for specific CHD ranged from 4\% (95\% CI 3-5\%) for non-operated VSD to $17 \%$ (95\% CI 9-31\%) for the ToF.

Table 3 shows the results of the ordinal logistic regression analysis for the five different types of CHD. There were substantial differences in the odds of both intermediate SGA and severe SGA across the five specific CHD.

In particular, the odds of overall and severe SGA were substantially higher for operated VSD and for ToF as compared with minor non-operated VSD; the adjusted odds ratios from the ordinal logit model were 2.1 (95\% CI, 1.1-3.8) and 2.7 (95\% CI, 1.3-5.8) for operated VSD and ToF, respectively.

\section{DISCUSSION}

Using population-based data from a large prospective cohort of children born with isolated $\mathrm{CHD}$, we found that the overall
TABLE 1 | Characteristics of the study population: EPICARD Study.

\begin{tabular}{|c|c|c|c|}
\hline & $N$ & $\%$ & $95 \% \mathrm{Cl}$ \\
\hline \multicolumn{4}{|l|}{ Sex } \\
\hline Male & 847 & 47 & $45-50$ \\
\hline \multicolumn{4}{|l|}{ Preterm birth (< 37 weeks) } \\
\hline Yes & 192 & 11 & $9-12$ \\
\hline \multicolumn{4}{|l|}{ Smoking during pregnancy } \\
\hline Yes & 50 & 3 & $2-4$ \\
\hline \multicolumn{4}{|l|}{ Maternal diabetes } \\
\hline Yes & 25 & 1 & $1-2$ \\
\hline \multicolumn{4}{|l|}{ Maternal illicit drug use } \\
\hline Yes & 10 & 1 & $0-1$ \\
\hline \multicolumn{4}{|l|}{ Maternal age } \\
\hline$<29$ & 675 & 38 & $36-40$ \\
\hline $30-34$ & 650 & 37 & 34-39 \\
\hline $35-39$ & 343 & 19 & $18-21$ \\
\hline$>40$ & 111 & 6 & $5-7$ \\
\hline \multicolumn{4}{|l|}{ Parity } \\
\hline 0 & 638 & 36 & $34-38$ \\
\hline 1 & 545 & 31 & $29-33$ \\
\hline$>2$ & 595 & 33 & $31-36$ \\
\hline \multicolumn{4}{|l|}{ Maternal geographic origin } \\
\hline France & 907 & 51 & $49-53$ \\
\hline North Africa & 330 & 19 & $17-20$ \\
\hline Sub Saharan Africa & 217 & 12 & $11-14$ \\
\hline Other & 329 & 18 & $17-20$ \\
\hline \multicolumn{4}{|c|}{ Maternal high blood pressure } \\
\hline Yes & 22 & 1 & $1-2$ \\
\hline \multicolumn{4}{|l|}{ Prenatal diagnosis of $\mathrm{CHD}$} \\
\hline Yes & 313 & 17 & $16-19$ \\
\hline \multicolumn{4}{|c|}{ Assisted reproductive technologies } \\
\hline Yes & 124 & 7 & $6-8$ \\
\hline \multicolumn{4}{|l|}{ Small for gestational age } \\
\hline Normal & 1,554 & 87 & $85-88$ \\
\hline$<$ 10th percentile & 235 & 13 & $12-15$ \\
\hline 3rd-10th percentile & 142 & 8 & $7-9$ \\
\hline$<3 r d$ percentile & 93 & 5 & $4-6$ \\
\hline \multirow[t]{2}{*}{ Birth weight (gr) } & Mean & $S D$ & \\
\hline & 3,175 & 618.71 & $3,147-3,204$ \\
\hline Total number of patients & 1,789 & & \\
\hline
\end{tabular}

prevalence of SGA was $13 \%$ and that of severe SGA 5\%, both of which are higher than the expected proportions in the general population, 10 and 3\%, respectively, based on the EPOPé population-based growth curves in France $(7,11)$.

We also found important differences in the probability of SGA and of severe SGA across the different types of CHD. In particular, VSD, which required surgery and Tetralogy of Fallot were associated with two- to three-folds higher odds of both intermediate and severe SGA, whereas minor VSD that did not require surgery was not associated with any significant increase in the risk of SGA as compared with the expected proportions in the general population. Whereas, newborns with SGA as a whole may include those who are constitutionally small, our findings 
TABLE 2 | Proportions of SGA ( $<10$ th percentile), intermediate SGA ( $\geq 3$ rd percentile $<10$ th percentile), and severe SGA ( $<3 r d$ percentile) for all isolated CHD, major isolated $\mathrm{CHD}$, and isolated specific CHD.

\begin{tabular}{|c|c|c|c|c|c|c|c|c|c|c|}
\hline & \multirow[b]{2}{*}{ Total } & \multicolumn{3}{|c|}{ SGA } & \multicolumn{3}{|c|}{ Intermediate SGA } & \multicolumn{3}{|c|}{ Severe SGA } \\
\hline & & $N$ & $\%$ & $95 \% \mathrm{Cl}$ & $N$ & $\%$ & $95 \% \mathrm{Cl}$ & $N$ & $\%$ & $95 \% \mathrm{Cl}$ \\
\hline All isolated CHD & 1,789 & 235 & 13 & $12-15$ & 142 & 8 & $7-9$ & 93 & 5 & $4-6$ \\
\hline All isolated major $\mathrm{CHD}$ & 493 & 78 & 16 & $13-19$ & 51 & 10 & $8-13$ & 27 & 6 & $4-8$ \\
\hline \multicolumn{11}{|l|}{ Specific isolated CHD } \\
\hline ToF & 53 & 14 & 26 & $16-40$ & 6 & 11 & $5-24$ & 8 & 15 & $8-28$ \\
\hline TGA & 78 & 9 & 12 & $6-21$ & 8 & 10 & $5-19$ & 1 & 1 & $0-9$ \\
\hline CoA & 71 & 12 & 17 & $10-28$ & 6 & 9 & $4-18$ & 6 & 9 & $4-18$ \\
\hline $\mathrm{FUH}$ & 36 & 7 & 19 & $9-36$ & 3 & 8 & $3-24$ & 4 & 11 & $4-27$ \\
\hline Operated VSD & 128 & 27 & 21 & $15-29$ & 16 & 13 & $8-20$ & 11 & 9 & $5-15$ \\
\hline Non-Operated VSD & 1,063 & 113 & 11 & $9-13$ & 69 & 6 & $5-8$ & 44 & 4 & $3-6$ \\
\hline
\end{tabular}

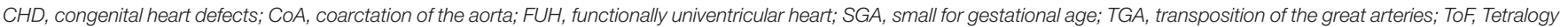
of Fallot; VSD, ventricular septal defects.

TABLE 3 | Odds ratios of SGA (severe and intermediate vs. normal) for different types of isolated CHD by ordinal logistic regression.

\begin{tabular}{|c|c|c|c|c|}
\hline & Crude odds ratio & $95 \% \mathrm{Cl}$ & Adjusted odds ratio** & $95 \% \mathrm{Cl}$ \\
\hline Minor ventricular septal defect (VSD) & Reference & & Reference & \\
\hline Operated ventricular septal defect (VSD) & 2.8 & $1.6-4.8$ & 2.0 & $1.1-3.8$ \\
\hline Univentricular heart (UVH) & 2.2 & $0.9-5.1$ & 2.0 & $0.7-5.5$ \\
\hline Tetralogy of Fallot (ToF) & 3.3 & $1.7-6.2$ & 2.7 & $1.3-5.8$ \\
\hline Transposition of great arteries (TGA) & 1.1 & $0.5-2.2$ & 1.1 & $0.5-2.5$ \\
\hline Coarctation of the aorta (CoA) & 1.8 & $0.9-3.4$ & 1.4 & $0.6-3.0$ \\
\hline
\end{tabular}

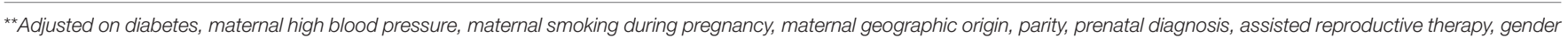
and prematurity.

were similar when we looked at severe SGA (birthweight $<3$ rd percentile) and the latter is considered, by definition, to represent growth restriction at birth (12).

Our findings on the overall proportion of SGA for isolated $\mathrm{CHD}$ are comparable with a previous systematic review (3). However, previous data summarized in this systematic review did not allow estimates for severe SGA or for comparison of proportions of SGA across different types of CHD. Variations in the proportions of SGA and severe SGA for different $\mathrm{CHD}$ as reported in our study may provide insights into the pathophysiological mechanisms that link CHD with growth restriction at birth.

Two potential mechanisms may explain the relation between $\mathrm{CHD}$ and growth restriction at birth in general and in the case of differences across various types of CHD in particular. These include altered fetal hemodynamics and placental anomalies.

Matthieson et al. studied placental weight $\mathrm{z}$ scores in a Danish cohort of 7,569 children with CHD. They found that ToF and major VSD had lower placental weight which was in turn correlated with reduced birth weight and head circumference $\mathrm{z}$ scores (13).

Jones et al. found increased placental leptin secretion in children born with hypoplastic left heart syndrome and SGA (14). They argued that placental insufficiency results in SGA through reduced angiogenesis, which in turn reduces the surface area for gaseous exchange.
There may also be common etiological factors that cause both CHD and placental anomalies. Nitric oxide synthase (NOS) deficiency may be the common etiological factor that results in both CHD and fetal growth restriction. Liu et al. found that NOS was important in fetal heart development with deficiencies resulting in CHD (15). Other studies have shown that endothelial NOS may play an important role in fetal growth $(16,17)$.

Another possible mechanism is that alterations in blood flow circulation, result in differential perfusion and/or oxygen supply in the fetal body, which may in turn cause growth restriction in certain types of CHD but not necessarily others.

Wallenstein et al. found that CHD are associated with growth restriction and based on previous works by Rizzo et al. and Lutin et al., they argued that decreased ventricular output results in SGA but this may only occur in CHD with altered ventricular function $(4,18,19)$. Using cardiovascular magnetic resonance, Al Nafsi et al. found that superior vena cava blood flow varied in left sided CHD compared to controls without CHD (20). Story et al. also found differences in the proportion of SGA in specific CHD, notably 13\% SGA in TGA, 17\% SGA in CoA and $26 \%$ SGA in ToF (results similar to those in our study) (5). The authors hypothesized that growth restriction for ToF was due to decreased fetal blood flow and hence reduced oxygenation. This may only be true however, in case of fetal heart failure or when the arterial duct is absent or closed. They also reported that newborns with CoA have decreased overall birthweight and 
length but normal head circumference and a greater head volume to birthweight ratio. The latter may be due to decreased caudal blood flow (without a decrease in oxygen saturation.

Donfrio et al. used Doppler ultra sound to demonstrate that decreased blood oxygenation due to abnormal fetal hemodynamics results in enhanced cerebral blood perfusion (brain sparing effect) as an adaptive compensatory mechanism in single ventricle defects (hypolastic left and right syndromes) (21). However, enhanced cerebral perfusion occurs at the expense of fetal liver, renal, pancreatic and mesenteric circulation, which in turn results in decreased production of insulin growth factor, angiotensin and other endocrine hormones essential for fetal growth (22). These hormones may affect the fetal growth directly as is the case of insulin growth factor or indirectly via placental function (e.g., renin-angiotensin system), inducing an inflammatory response or through other biomolecular pathways $(23,24)$.

Alternatively, abnormal fetal hemodynamics may affect the placenta resulting in SGA either through elevated fetoplacental vascular resistance due to placental ischemia or by fetoplacental endothelial dysregulation which plays a key role in tempering inflammatory regulators and nutrient exchange (25). Nevertheless, in general, the underlying pathophysiological mechanisms of the associations (or lack thereof) between CHD and the risk of growth restriction are complex and most likely involve multifactorial causal pathways and compensatory mechanisms that are not completely understood. Moreover, in addition to the placental and fetal hemodynamic mechanisms, there are also genetic and epigenetics factors related to the risk of growth restriction with CHD (26-28).

Our study has certain limits. Our study was not designed and cannot disentangle the possible mechanisms that may explain our empirical findings. Indeed, investigation of the possible underlying mechanisms of the relation between CHD and fetal growth were beyond the scope or ambition of our study.

In addition, even if data were from a large, population-based of newborns with $\mathrm{CHD}$, the number of cases for individual specific CHD was relatively small, which resulted in reduced precision in our estimates, particularly for the fortunately less common severe SGA outcomes. However, by using the ordinal logit model, which allowed looking at both severe and intermediate SGA outcomes in the same model, we were able to increase the statistical power of our study, including for severe SGA outcome $(9,10)$.

\section{Conclusion}

Congenital heart defects are associated with a higher risk of growth restriction at birth, including a higher risk of severe growth restriction.

The risk of growth restriction was substantially higher for certain types of CHD, notably operated ventricular septal defects and the Tetralogy of Fallot. The underlying mechanisms of the relation between $\mathrm{CHD}$ and growth restriction at birth may be hypoxia and alternations in blood perfusion in the fetus. In addition, placenta is likely to play an important role in the causal links between CHD and fetal growth restriction. Future studies are needed to disentangle the underlying mechanisms, including genetic and epigenetic factors that may explain the higher risk of growth restriction for newborns with congenital heart defects.

\section{DATA AVAILABILITY STATEMENT}

The original contributions presented in the study are included in the article/supplementary material, further inquiries can be directed to the corresponding author/s.

\section{ETHICS STATEMENT}

The studies involving human participants were reviewed and approved by CNIL (French National Committee of information and Liberty). Written informed consent to participate in this study was provided by the participants' legal guardian/next of kin.

\section{EPICARD STUDY GROUP}

Principal Investigators: François Goffinet, Babak Khoshnood.

Steering Committee: Damien Bonnet (Hôpital Necker Enfants Malades, AP-HP, Center de référence M3C, Université Paris Descartes, Paris), Johanna Calderon (INSERM U1153), Drina Candilis (Université Paris-Diderot, Paris), Anne-Lise Delezoide (Hôpital Robert Debré, AP-HP, Service de biologie du Développement, Université Paris-Diderot, Paris), Catherine De Vigan (INSERM 1153, Paris), François Goffinet (Groupe Hospitalier Cochin-Hôtel Dieu, AP-HP, Maternité Port-Royal et INSERM U953, Université Paris Descartes, Paris), Lucile Houyel (Hôpital Marie Lannelongue, Service de chirurgie des cardiopathies congénitales, Le Plessis-Robinson), Jean-Marie Jouannic (Hôpital Trousseau, AP-HP, Center pluridisciplinaire de diagnostic prénatal, UPMC, Paris), Babak Khoshnood (INSERM U1153, Paris), Nathalie Lelong (INSERM U1153, Paris), Suzel Magnier (Hôpital Robert Debré, AP-HP, Service de cardiologie, Paris), Jean-François Magny (Institut de Puériculture et de périnatologie, Service de néonatologie, Paris), Caroline Rambaud (Hôpital Raymond Poincarré, AP-HP, Service d'anatomie et cytologie pathologiques - Médecine légale, UVSQ, Garches), Dominique Salomon (INSERM U1153, Paris), Véronique Vodovar (INSERM U1153, Paris).

Project Coordination and Data Analysis Committee: François Goffinet, Babak Khoshnood, Nathalie Lelong, Anne-Claire Thieulin, Thibaut Andrieu, Véronique Vodovar.

Independent Data Monitoring Committee (URC Paris Center et CIC Cochin Necker Mère Enfant): Maggy Chausson, Anissa Brinis, Laure Faure, Maryline Delattre, Jean-Marc Treluyer (Groupe Hospitalier Cochin-Hôtel Dieu, AP-HP, Université Paris Descartes, Paris).

External Scientific Committee: Gérard Bréart, Dominique Cabrol, Alain Sérraf, Daniel Sidi, Marcel Voyer.

Participating Centers: The Greater Paris Area (Paris and its surrounding suburbs) public (AP-HP) and private maternity units, Departments of Pediatric Cardiology and Pediatric Cardiac Surgery, pediatric cardiologists in private practice, Neonatal Intensive Care Units, Pediatric Intensive Care 
Units, Emergency Transfer Services (SMUR), Departments of Pathology, Sudden Death Centers, Departments of Family and Infant Protection (DFPE).

\section{AUTHOR CONTRIBUTIONS}

BK conceived the study. AG conducted the statistical analyses and wrote the first draft of the manuscript. DB, FG, and $\mathrm{BK}$ contributed to the conceptualization of ideas and

\section{REFERENCES}

1. Lindinger A, Schwedler G, Hense HW. Prevalence of congenital heart defects in newborns in Germany: results of the first registration year of the PAN Study (July 2006 to June 2007). Klinische Pädiatrie. (2010) 222:321-6. doi: $10.1055 / \mathrm{s}-0030-1254155$

2. Van Der Linde D, Konings EE, Slager MA, Witsenburg M, Helbing WA, Takkenberg JJ, et al. Birth prevalence of congenital heart disease worldwide: a systematic review and meta-analysis. J Am College Cardiol. (2011) 58:2241-7. doi: 10.1016/j.jacc.2011.08.025

3. Ghanchi A, Derridj N, Bonnet D, Bertille N, Salomon LJ, Khoshnood B. Children born with congenital heart defects and growth restriction at birth: a systematic review and meta-analysis. Int J Environ Res Public Health. (2020) 17:3056. doi: 10.3390/ijerph17093056

4. Wallenstein MB, Harper LM, Odibo AO, Roehl KA, Longman RE, Macones GA, et al. Fetal congenital heart disease and intrauterine growth restriction: a retrospective cohort study. J Maternal-Fetal Neonatal Med. (2012) 25:662-5. doi: $10.3109 / 14767058.2011 .597900$

5. Story L, Pasupathy D, Sankaran S, Sharland G, Kyle P. Influence of birthweight on perinatal outcome in fetuses with antenatal diagnosis of congenital heart disease. J Obstet Gynaecol Res. (2015) 41:896-903. doi: 10.1111/jog.12652

6. Khoshnood B, Lelong N, Houyel L, Thieulin AC, Jouannic JM, Magnier S, EPICARD Study Group. Prevalence, timing of diagnosis and mortality of newborns with congenital heart defects: a population-based study. Heart. (2012) 98: 1667-73. doi: 10.1136/heartjnl-2012-302543

7. Ego A, Prunet C, Lebreton E, Blondel B, Kaminski M, Goffinet F, et al. Courbes de croissance in utero ajustées et non ajustées adaptées à la population française. I-Méthodes de construction. J Gynécol Obstétrique Biol Reproduction. (2016) 45:155-64. doi: 10.1016/j.jgyn.2015.08.009

8. Ego A. Définitions: petit poids pour l'âge gestationnel et retard de croissance intra-utérin [Definitions: small for gestational age and intrauterine growth retardation]. J Gynecol Obstet Biol Reprod. (2013) 42:872-94. doi: 10.1016/j.jgyn.2013.09.012

9. Bender R, Grouven U. Ordinal logistic regression in medical research. J Royal College Phys London. (1997) 31:546.

10. Warner P. Ordinal logistic regression. BMJ Sexual Reproductive Health. (2008) 34:169-70. doi: 10.1783/147118908784734945

11. Ego A, Prunet C, Blondel B, Kaminski M, Goffinet F, Zeitlin J. Customized and non-customized French intrauterine growth curves. II-Comparison with existing curves and benefits of customization. J Gynecol Obstetrique Biol Reproduction. (2015) 45:165-76. doi: 10.1016/j.jgyn.2015.08.008

12. Beune IM, Bloomfield FH, Ganzevoort W, Embleton ND, Rozance PJ, van Wassenaer-Leemhuis AG, et al. Consensus based definition of growth restriction in the newborn. J Pediatrics. (2018) 196:71-6. doi: 10.1016/j.jpeds.2017.12.059

13. Matthiesen NB, Henriksen TB, Gaynor JW, Agergaard P, Bach CC, Hjortdal VE, et al. Congenital heart defects and indices of fetal cerebral growth in a nationwide cohort of 924422 liveborn infants. Circulation. (2016) 133:566-55. doi: 10.1161/CIRCULATIONAHA.115.019089

14. Jones HN, Olbrych SK, Smith KL, Cnota JF, Habli M, Ramos-Gonzales O, et al. Hypoplastic left heart syndrome is associated with structural and vascular placental abnormalities and leptin dysregulation. Placenta. (2015) 36:1078-86. doi: 10.1016/j.placenta.2015.08.003

15. Liu Y, Feng Q. NOing the heart: role of nitric oxide synthase-3 in heart development. Differentiation. (2012) 84:54-61. doi: 10.1016/j.diff.2012.04.004 made suggestions about the required analyses. All authors contributed to the interpretation of findings and revisions of the article.

\section{FUNDING}

This project financed by APHP DRCI and Association pour la Recherche en Cardiologie du Foetus à l'Adulte (ARCFA).

16. Lyall F, Greer IA, Young A, Myatt L. Nitric oxide concentrations are increased in the feto-placental circulation in intrauterine growth restriction. Placenta. (1996) 17:165-8. doi: 10.1016/S0143-4004(96)80009-9

17. Kulandavelu S, Whiteley KJ, Bainbridge SA, Qu D, Adamson SL. Endothelial NO synthase augments fetoplacental blood flow, placental vascularization, and fetal growth in mice. Hypertension. (2013) 61:259-66. doi: 10.1161/HYPERTENSIONAHA.112.201996

18. Rizzo G, Capponi A, Rinaldo D, Arduini D, Romanini C. Ventricular ejection force in growth-retarded fetuses. Ultrasound Obstet Gynecol. (1995) 5:247-55. doi: 10.1046/j.1469-0705.1995.05040247.x

19. Lutin WA, Brumund MR, Jones C, Tharpe CE, Montegomery M, McCaffrey FM. Hemodynamic abnormalities in fetuses with congenital heart disease. Pediatric Cardiology. (1999) 20:390-5. doi: 10.1007/s002469900497

20. Al Nafisi B, van Amerom JF, Forsey J, Jaeggi E, Grosse-Wortmann L, Yoo SJ, et al. Fetal circulation in left-sided congenital heart disease measured by cardiovascular magnetic resonance: a case-control study. J Cardiovasc Magn Reson. (2013) 15:1-12. doi: 10.1186/1532-429X-15-65

21. Donofrio MT, Bremer YA, Schieken RM, Gennings C, Morton LD, Eidem BW, et al. Autoregulation of cerebral blood flow in fetuses with congenital heart disease: the brain sparing effect. Pediatric Cardiol. (2003) 24:436-43. doi: 10.1007/s00246-002-0404-0

22. Ebbing C, Rasmussen S, Godfrey KM, Hanson MA, Kiserud T. Redistribution pattern of fetal liver circulation in intrauterine growth restriction. Acta Obstet Gynecol Scand. (2009) 88:1118-23. doi: 10.1080/00016340903214924

23. Delforce SJ, Lumbers ER, Ellery SJ, Murthi P, Pringle KG. Dysregulation of the placental renin-angiotensin system in human fetal growth restriction. Reproduction. (2019) 158:237-45. doi: 10.1530/REP-18-0633

24. Tang L, He G, Liu X, Xu W. Progress in the understanding of the etiology and predictability of fetal growth restriction. Reproduction. (2017) 153:R227-40. doi: 10.1530/REP-16-0287

25. Su EJ. Role of the fetoplacental endothelium in fetal growth restriction with abnormal umbilical artery Doppler velocimetry. Am J Obstetrics Gynecol. (2015) 213:S123-30. doi: 10.1016/j.ajog.2015.06.038

26. Vecoli C, Pulignani S, Foffa I, Grazia Andreassi M. Congenital heart disease: the crossroads of genetics, epigenetics and environment. Curr Genom. (2014) 15:390-9. doi: 10.2174/1389202915666140716175634

27. Schulkey CE, Regmi SD, Magnan RA, Danzo MT, Luther H, Hutchinson $\mathrm{AK}$, et al. The maternal-age-associated risk of congenital heart disease is modifiable. Nature. (2015) 520:230-3. doi: 10.1038/nature14361

28. Chowdhury S, Cleves MA, MacLeod SL, James SJ, Zhao W, Hobbs A, et al. Maternal DNA hypomethylation and congenital heart defects. Birth Defects Res A Clin Mol Teratol. (2011) 91:69-76. doi: 10.1002/bdra. 20761

Conflict of Interest: The authors declare that the research was conducted in the absence of any commercial or financial relationships that could be construed as a potential conflict of interest.

Copyright () 2021 Ghanchi, Rahshenas, Bonnet, Derridj, LeLong, Salomon, Goffinet and Khoshnood. This is an open-access article distributed under the terms of the Creative Commons Attribution License (CC BY). The use, distribution or reproduction in other forums is permitted, provided the original author(s) and the copyright owner(s) are credited and that the original publication in this journal is cited, in accordance with accepted academic practice. No use, distribution or reproduction is permitted which does not comply with these terms. 